\title{
Photographic Representation, Popular Memory and Historical Consciousness: Through the Lens of Roman Vishniac
}

\author{
A. M. Givertz \& Marcus Klee
}

"It is a vanished but not vanquished world, captured here

in images made with hidden cameras." Roman Vishniac

Photographic technology originated from the combination of a modified camera obscura - a "black box" employed by artists such as Leonardo da Vinci to address problems of perspective and colour in landscape painting by displaying an image through a pencil sized hole - with chemically coated plates capable of capturing a reflected image. The "Daguerreotype" camera, invented in France in 1839, was quickly embraced and used to produce three million portraits a year in America alone during the 1850 s. $^{1}$ As a popular extension of the painted portrait, this and newer photographic technologies such as the flexible cellulose film based cameras produced by Kodak, allowed for, and in some fashion structured, new ways of remembering and making sense of our past.

Raymond Williams observed that photographic technologies arose during "a period of great mobility, with new separations of families and with internal and external migrations," and served as a means "of maintaining, over distance and through time, certain personal connections." 2 Photo albums containing images of faces and places not only invoke sentimental, and often distorted, reminiscence part of what Walter Benjamin called the "cult of remembrance of loved ones, absent or dead"3 - but allow us to construct and reconstruct essential personal narratives. From these frozen and isolated moments of our past, we string together an understanding of who we are, where we have been, and the relationships that have marked us.

The reproduction of photographs on a mass scale, via photo-journalism and pictorial magazines after 1890 , displaced the family photo from its primary position at the centre of the "cult of remembrance." Benjamin sees the work of the French photographer Eugene Atget as ushering in an era when photographs became "standard evidence for historical occurrences, and acquire[d] a hidden political signifi-

\footnotetext{
Melvin L. De Fleur, Theories of Mass Communication (New York 1972), 24-25, 31.

Raymond Williams, Television: Technology and Cultural Form (New York 1975), 22.

Walter Benjamin, "Art in the Age of Mechanical Reproduction," in John G. Hanhardt, ed., Video Culture: A Critical Investigation (Rochester, N.Y. 1986), 34.
} 


\section{0 left history}

cance." 4 As historical evidence, offering exact reproductions of the moment or a transparent means to knowledge, their use represented a "conquest of the machine that can observe things," even if they could "be used for the liberation or for the oppression of mankind [sic]"s (surveillance or exposition).

The rise of photo-journalism initiated the use of the camera to provide "mechanical and thus 'scientifically' observable evidence or 'data.' Photographs are seen as sources of factual, positive knowledge, and thus are appropriate documents for a history that claims a place among the supposedly objective sciences of human behaviour." 6 But the photograph does not simply reflect reality, it interprets reality. Photographic technique can bring out aspects of reality which are imperceivable to the naked eye. What is seen and what is not seen alerts us of the need to problematize the use of photographs as historical evidence.

Photographs represent desitutated fragments, abstracted from complex histories, with "much less fixed and unequivocal meaning than we commonly acknowledge," and only read within the boundaries of our subjectivities. ${ }^{8}$ Still, there is a certain neutrality, however fragile, to the photographic medium. As Ulrich Keller posits, "the camera's eye is less docile than brush or pen ... represent[ing] a complex blend of what the photographer wanted to record and what the camera happened to capture." Or as H. F. Talbot argues, photography allows "objects to inscribe themselves on the picture surface." 9

We offer Roman Vishniac's photographs of Jewish life in Poland, taken immediately before the Second World War, as one such problematic. Described by Elie Wiesel as the "Poet of memory, elegist of ruined hopes," ${ }^{10}$ his work is starkly beautiful, some might say haunting. We include these photographs because of their artistry, but also because their usefulness as historical documents is complex. We have not provided a textual analysis and we intentionally neglected to include Vishniac's captions. Instead, we choose to simply introduce his work.

4 Ibid., 34.

5 Franz Höllering, "The Conquest of the Machines That Can Observe Things," in Armand Mattelart and Seth Sieglaub, eds., Communication and Class Struggle, Vol. 2 (New York 1982), 174.

6 Alan Sekula, "Photography Between Labour and Capital," in Leslie Shedden, Mining Photographs and Other Picture: A Selection from the Negative Archives of Shedden Studio, Glace Bay, Cape Breton, 1948-1968 (Halifax \& Cape Breton 1983), 198.

7 Lucjan Dobroszycki and Barbara Kirshenblatt-Gimblett, Images Before My Eyes: A Photographic History of Jewish Life in Poland, 1864-1939 (New York 1977).

8 Ulrich Keller, "Introduction," in U. Keller, ed., The Warsaw Ghetto in Photographs: 206 Views Made in 1941 (New York 1984), xvii. Also see A. Sekula, "On the Invention of Photographic Meaning," in V. Goldberg, ed., Photography in Print: Writings from 1816 to the Present (New York 1981).

9 Keller, "Introduction," xxii.

10 Elie Wiesel, "Foreword," A Vanished World (New York 1983). 
Roman Vishniac was born in 1897 in a Dacha near St. Petersburg to a wealthy family, his father was an umbrella manufacturer. The family actually lived in Moscow, which was unusal in Czarist Russia because Moscow was a city restricted to Christians. Their residence was one privilege of weal th. Vishniac began university in 1914, graduating with a Ph.D. in zoology and an M.D. in 1920. He later distinguished himself as a photomicrographologist, capturing discrete moments in the lives of insects and fish, revealing aspects of life normally hidden from the human eye. $\mathrm{He}$ was widely recognized as the author of Building Block's of Life (New York 1971), and as the subject of films like NBC-TV's The Big Little World of Roman Vishniac. ${ }^{11}$

While still in school, Vishniac had disguised himself as a Bolshevik irregular to help his family leave Soviet Russia (where anti-semitism had been made illegal), to go to Germany. In 1920 he joined his family in Germany. Vishniac lived in Berlin for nineteen years, holding a variety of jobs while studying Oriental art at the University of Berlin. Apparently he completed all the requirements for a Ph.D. but was denied his degree because he was Jewish.

The Nazi threat first revealed itself to him in the early thirties when he found himself in the middle of a demonstration against a Jewish-owned department store in downtown Berlin and once again when an editor at the magazine Volk und Rasse, not realizing that Vishniac was a Jew, commissioned him to produce two photomicrographs that would show "how the blood of a pure Aryan differed from that of a Jew." From this event he began four years of travel, returning periodically to Berlin to earn money, to create a photographic record of the Jews of Eastern Europe (primarily Poland), whom he believed would be the immediate victims of Nazi violence. "I was living in Germany in the thirties and I knew that Hitler had made it his mission to exterminate all Jews ... I was unable to save my people, only their memory." He took over 16,000 photos, all but 2,000 were destroyed - although they may well have ended up in a Nazi archivist's collection. His surviving photos were stored with his father who remained in hiding in France throughout the war. ${ }^{12}$

"Who was there to defend them?" he later asked. "I knew I could be of little help, but I decided that, as a Jew, it was my duty to my ancestors, who grew up among the very people who were being threatened, to preserve - in pictures, at least - a world that might soon cease to exist." 13 Similarly he reflected, "I thought maybe years and years after the killing, maybe the Jews will be interested to hear of the life that disappeared, of the life that is no more." 14 If Vishniac's mournful gaze is disturbing, it must be remembered that the Polish Jewry that he recorded was never restored. In

11 Eugene Kinkead, "The Tiny Landscape," in C. Capa and B. Karia, eds., Roman Vishniac (New York 1974), 6-15, 94.

12 Ibid., 6-17. His book Polish Jews: A Pictorial Record (New York 1947) was the first publication of the photos. Because of the publisher's interests, it was concerned primarily with Hasidic life and not economic hardship, something that disappointed Vishniac.

13 Eugene Kinkead, "The Tiny Landscape," 15-17.

14 Roman Vishniac, "The Life that Disappeared," in C. Capa and B. Karia, eds., Roman Vishniac (New York 1974), 52. 
1947 Vishniac returned to the locations of his photographs, his subjects had 'vanished': "After the war I visited these places, looking for survivors. I only found five men whom I knew ... Only the buildings stood where they were before." 15

Vishniac misunderstood the Nazi purpose, when he stated that Hitler "vowed to extinguish all memory of the Jews." ${ }^{16}$ In fact the Nazis, like Vishniac, constructed a detailed photographic/historical record of the Jewish people, capturing on film the same sites and maybe some of the same people that Vishniac had a few years earlier. That Vishniac and the Nazi camera are analogous should not surprise. Both were 'outsiders' - the distance between photographer and photographed is apparent; ${ }^{17}$ both 'knew' that the end of the subject was imminent. Both were rather clinical in method, seeking to observe and record, not liberate.

Nevertheless, crucial differences remain. Vishniac's photographs were taken before the invasion of Poland. Though he chronicled struggle the context was not of a people under siege, systematically starved by Nazis. He was not the agent of an oppressive state. Though his life experience was remote from their's, Vishniac expressed a familial connection to his subject with whom he felt an ancestorial link. In this sense, his work can be connected to other Jewish documentarians who worked in desperation to leave a record of their lives. And while they acted in direct defiance of the Nazis, Vishniac, like Mendel Grossman, who photographed the Lodz Ghetto under German occupation, acted as the agent of 'his' community. ${ }^{18}$

Ulrich Keller notes that since its inception the medium of photography has "oscillated between objective documentation and personal interpretation," accomplishing two purposes simultaneously, "that of personal explanation and that of plain record-keeping." In introducing his collection of Warsaw Ghetto photos taken by German army reporters, and members of Goebbels' Propaganda-Kompanien, he advises that a critical reading of these photos must take this ambiguity to mind. ${ }^{19}$ That said, the motives of the photographer need not be invoked in order to impose some sort of interpretive closure, but neither should intent be expunged from our reading of the text. Vishniac's photographs offer an ambiguous connection to a past destroyed by fascism and thus provide some sort of historical continuity. Consciousness is aroused by Vishniac's photography which turns memory into agency.

15 Ibid., 93, 57.

16 Roman Vishniac, "Preface," A Vanished World (New York 1983).

17 Edward Steichen, then director of photography at the Museum of Modern Art in New York, claimed that Vishniac's photos were "among photography's best of a time and place." Steichen incorrectly argued that Vishniac's strength flowed from a privileged insight, or he called "a native son's warmth and love for his people." Cited in Eugene Kinkead. "The Tiny Landscape," 18.

18 Z. Szner and A. Sened, With a Camera in the Ghetto. Mendel Grossman (New York 1977).

19 Ulrich Keller, "Introduction," ix. 


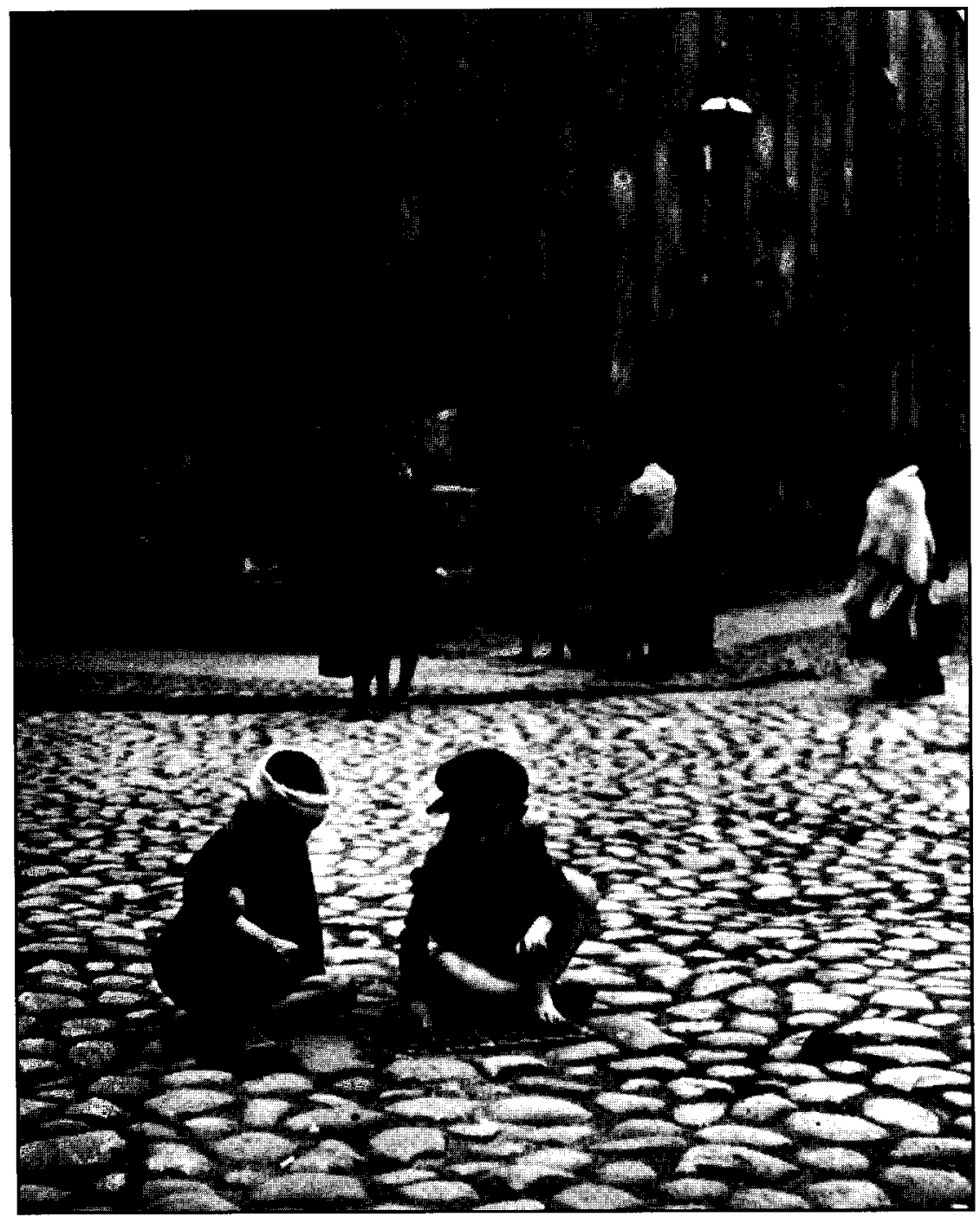




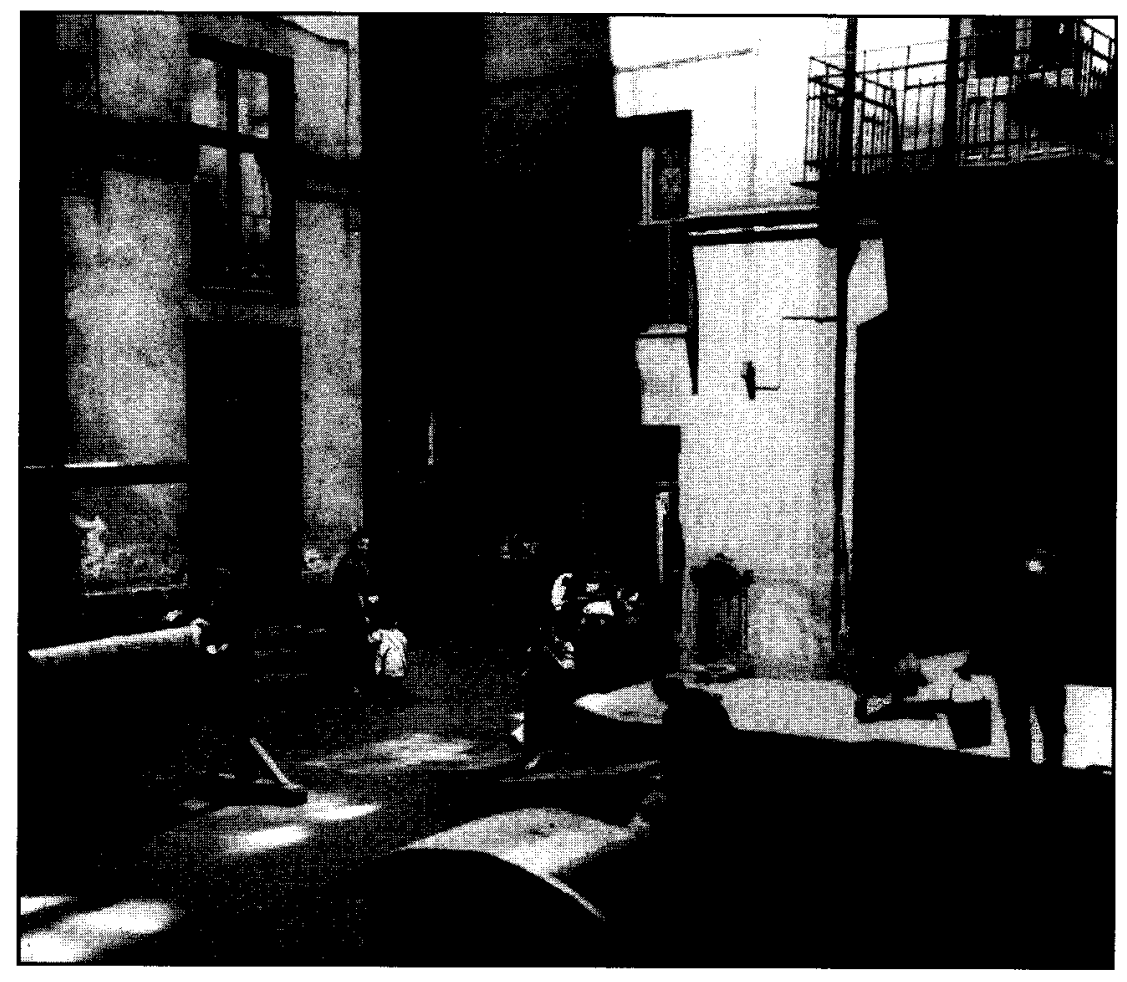


Roman Vishniac 155

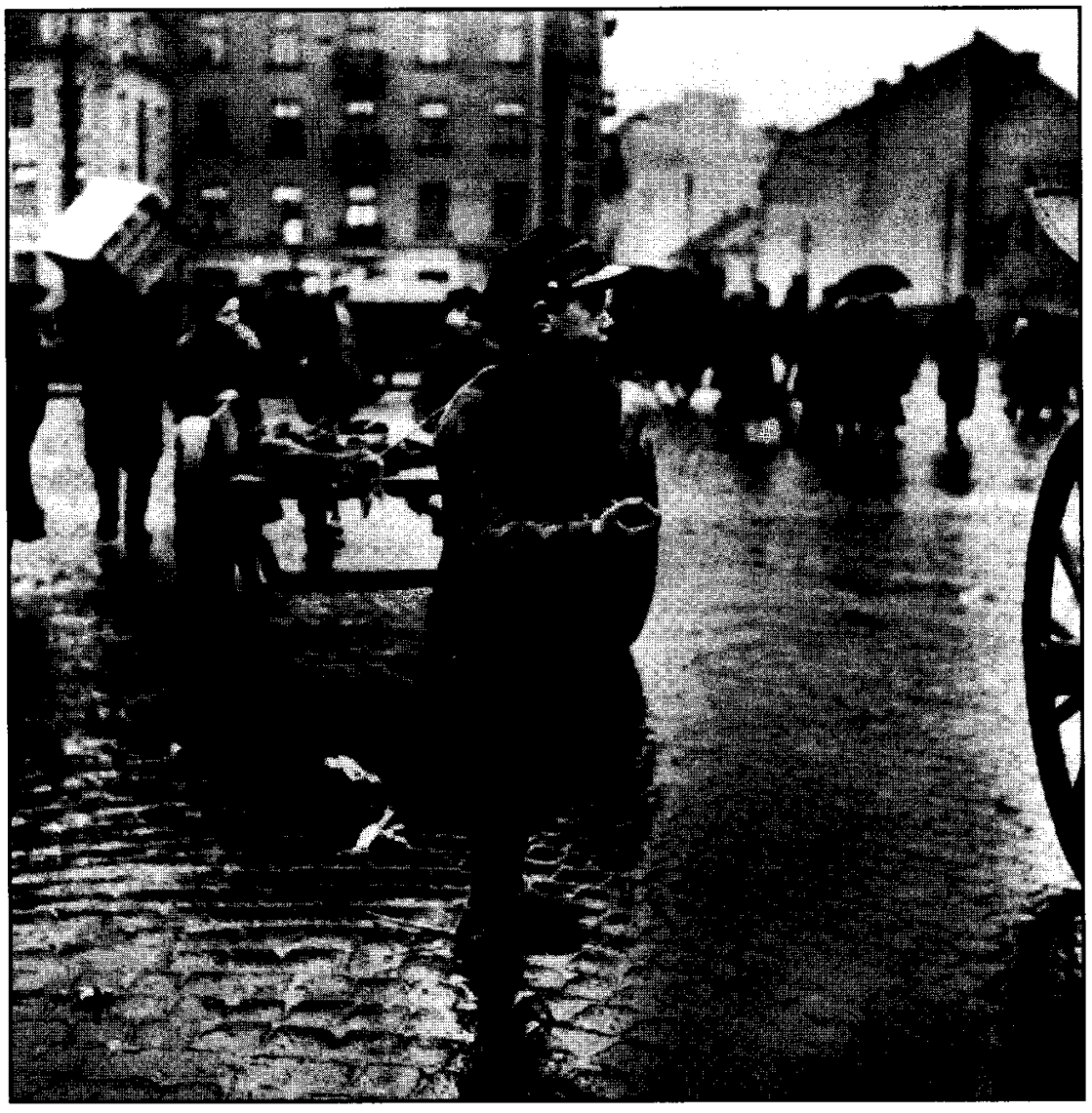


156 left history

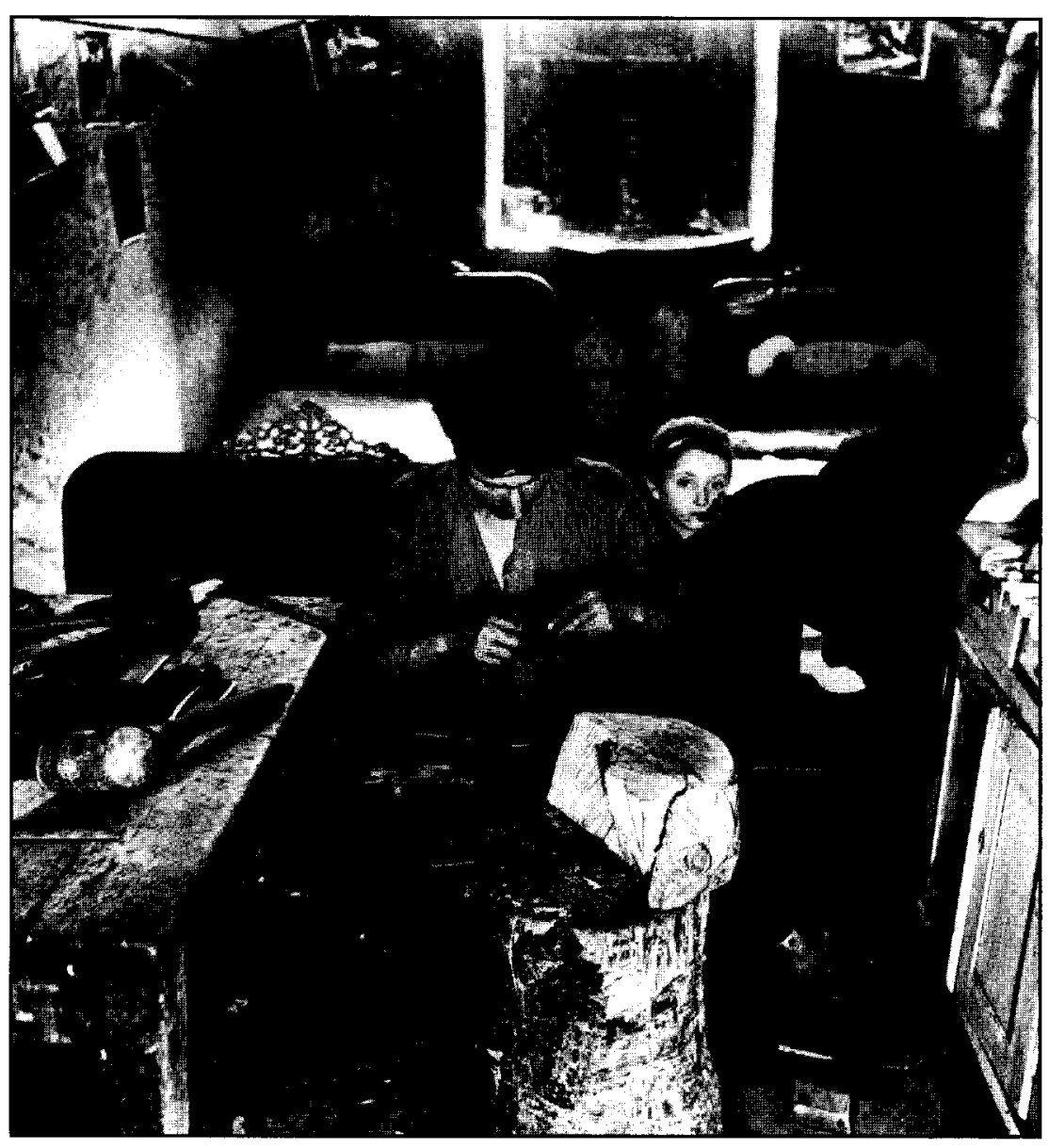




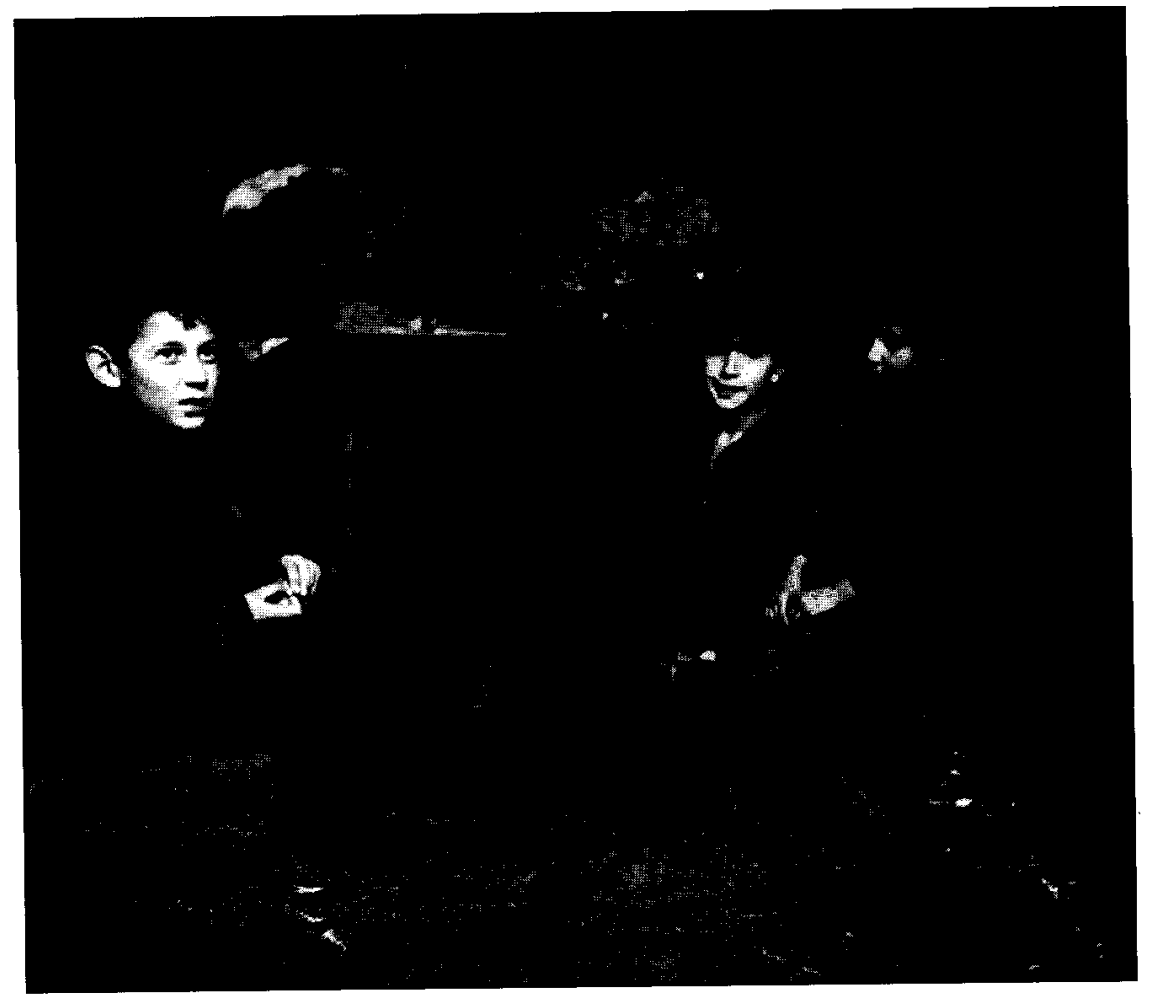




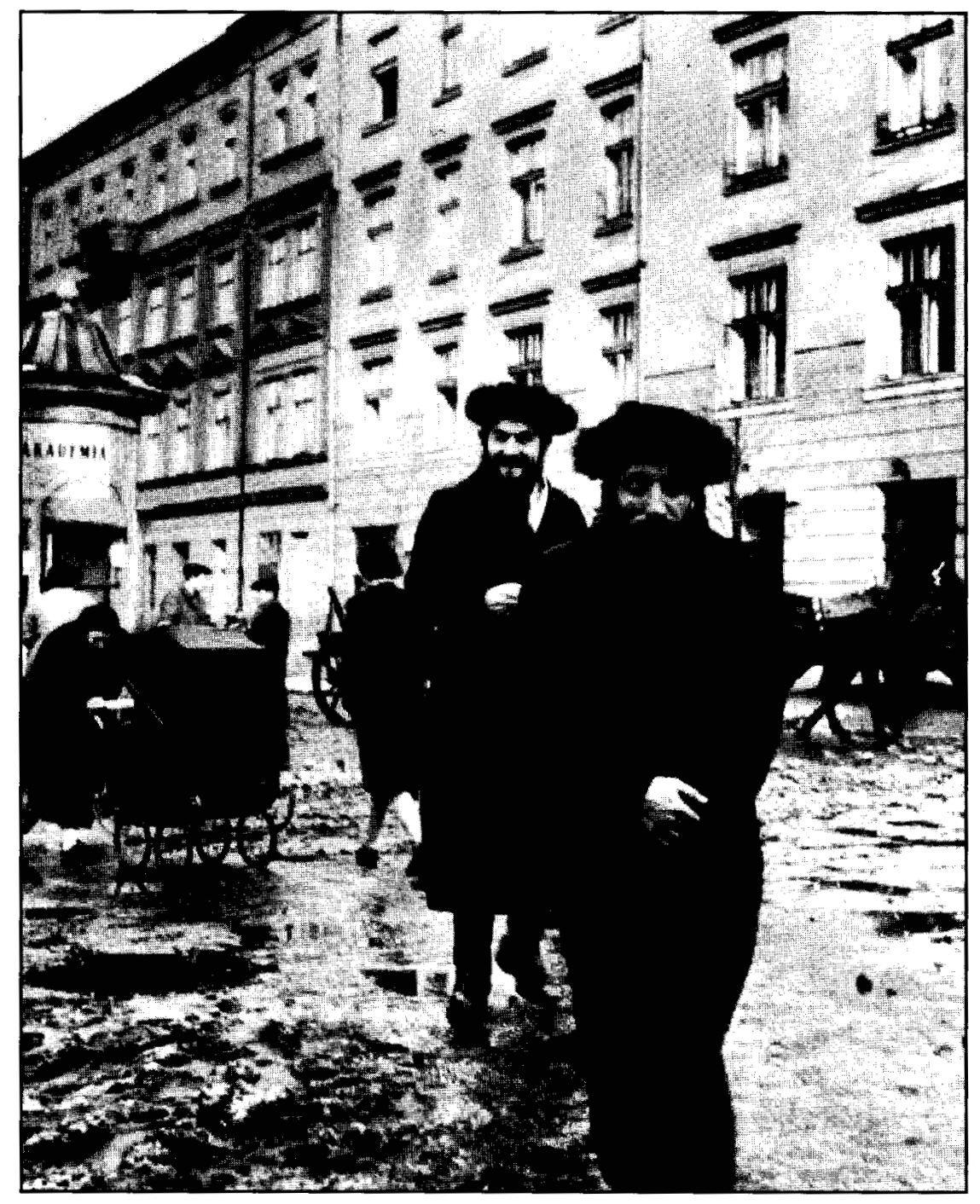


Roman Vishniac 159

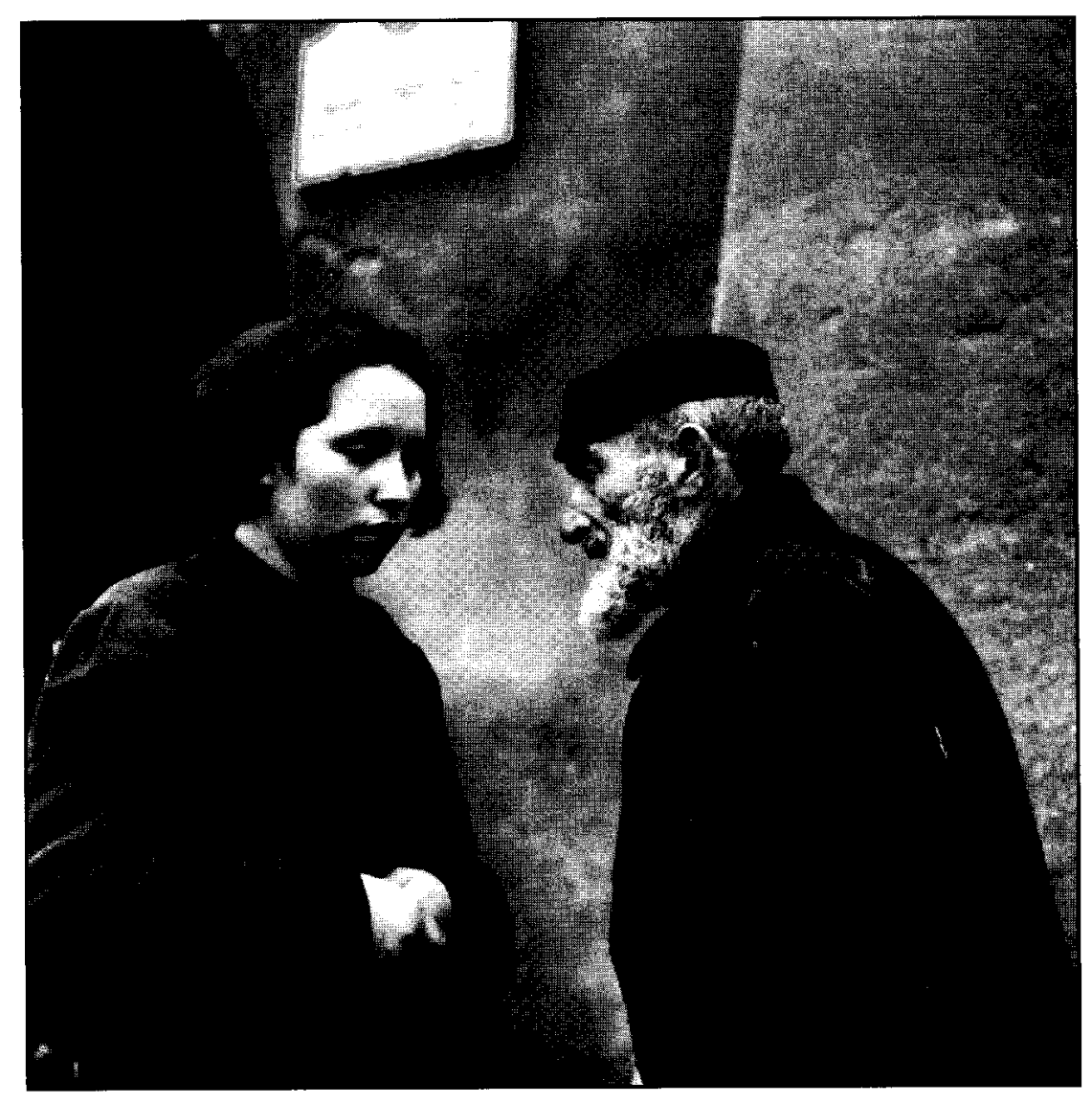


160 left history

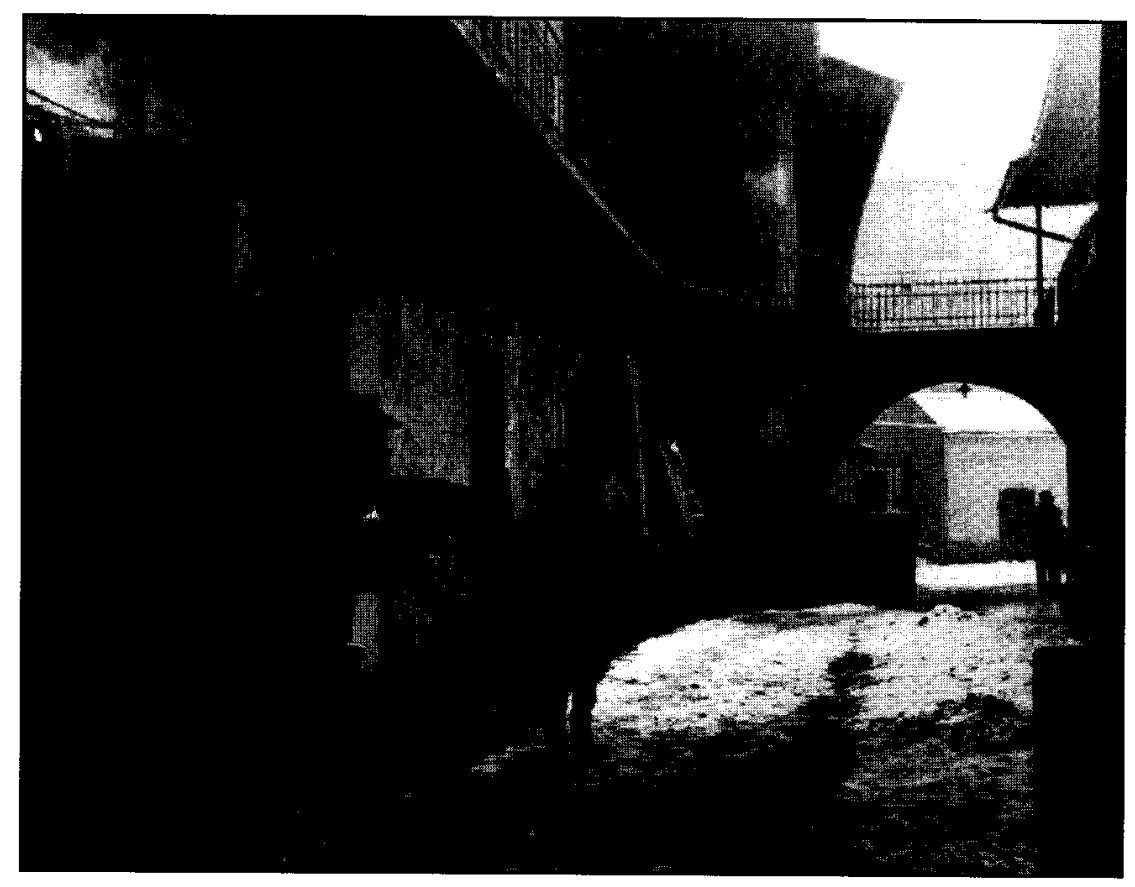

